Man's Place in the Island Ecosystem

A Symposium. Edited by F. R. Fosberg. Pp. vii +264 . (Honolulu, Hawaii: Bishop Museum Press, 1963.) 8 dollars.

$\mathrm{W}$ HEN the late Sir Arthur Tansley in 1935 introduced the term ecosystem and later defined it as "a unit of vegetation considered as a system . . includes not only the plants but also the animals habitually associated with them", it may be doubted whether he envisaged man as the most important animal concerned. Yet this is the logical conclusion, and where better to study the probloms involved than among the numorous and varied islands of the vast Pacific Ocean ? An island is a clearly defined areal unit; in the Pacific there is every stage from the uninhabited coral islet to the crowded sophisticated human atmosphere of the United States' fiftieth State. Under the Humid Tropies programme of Unesco, a symposium was arranged to take place at the tenth Pacific Science Congress held in the University of Hawaii at Honolulu in August 1961. It was very efficiently organized by Dr. F. R. Fosberg (Washington), aided by his able lieutenant, Dr. Marie-Hélène Sachet, and he contributes the short introductory paper on the ecosystem concept.

The major criticism must be that too much was attempted in the time allotted. Each of the thirteen papers is of the nature of an ex cathedra statement and each was followed by a comment by a 'discussant'limited to 3 or $5 \mathrm{~min}$, despite the fact that he might have been flown half-way around the world to take part. It was soon clear that no time would be available for discussion; in a few cases a question or two after the discussant had spoken. Many of the big names in the ecological field from all over the world are there-Marston Bates (Michigan), Pierre Gourou (Brussels), G. Mangenot (Paris), Irene Taeuber (Princeton), William L. Thomas (California), Kenneth Cumberland (New Zealand)-among the contributors; J. A. Steers, H. E. Maude among discussants; while a distinguished audience is revealed by simple questions from Paul Sears and C. F. A. Pantin. The task of a general summing up was left to Oskar Spate (Canberra).

The symposium is a landmark in the present development of thought. The ecosystem was the concept of a botanist mindful of the interaction of plants and animals and of the significance of the complex environment with its various physical factors. Here the influence of man brings in the physical and human geographer with the concept of human ecology fitting into the whole. The time to absorb the several contributions was lacking in Honolulu; this comprehensive report allows time for the proper and careful study of a series of papers of the highest value and significance. The sequence is logicalfrom physical environment and marine influence to the nature and evolution of the biota, the reciprocal mannature relationship, the pattern and varied nature of human influence and culture systems to the practical issues of the present problems of human pressure and demographic instabilities. This is an essential volume for every serious library.

L. Dudley Stamp (Discussant)

\section{A History of Parasitology}

By W. D. Foster. Pp. vi + 202. (London and Edinburgh: E. and S. Livingstone Ltd., 1965.) $35 s$.

THIS is a well-written and interesting book and I gained much pleasure and information from it. It is the first account of the history of parasitology written in English, and a book that has long been needed.

The author provides, in his first chapter, a succinct account of the growth of parasitology from ancient times. In succeeding chapters, in order to illustrate the basic discoveries of parasitology, he outlines the history of our knowledge of a series of animals parasitic in man.

He begins with the trematodes, and discusses the liver fluke, Fasciola hepatica, and the schistosomes, which cause bilharziasis, which is still one of the major diseases of man and at present the subject of a campaign organized by the World Health Organization. Four nematode types are then discussed, namely the hookworms, Trichinella spiralis, the Medina worm (Dracunculus medinensis), and Wuchereria bancrofti (a cause of filariasis). He next considers, in a separate chapter, the parasitic Protozoa. In the chapters that follow he treats the trypanosomes, Entamoeba histolytica, the cause of amoebic dysentery, and those other Protozoa, the babesias, which cause serious diseases of cattle and other farm stock. A final chapter brings the history up to about the year 1920, when parasitology became well established as a branch of biology.

This plan has certain advantages, but it does tend to direct attention to the animals parasitic in man only, and some readers will wish that more attention had been given to the achievements of veterinary parasitologists. It is true that their work on the babesias is discussed, but more space might have been given to the part played in the development of parasitology by co-operation between the veterinarians and workers concerned with diseases of man. Moreover, a chapter on the social and economic effects of parasitic animals and the devastating effects of some of them on the food supplies of the world would not have been out of place, for there is much evidence that animals parasitic in man have, through their social and oconomic effects, influenced appreciably the course of human history. Diseases caused by them have, for example, greatly influenced, if they have not actually determined, the outcome of wars. But themes such as these were no doubt outside the author's intention, which was, ho explains in his preface, "to give an accurate account of the basic discoveries of parasitology . . . at a level comprehensible to the non-professional parasitologist". In this general aim he has certainly succeeded. The book will be read with pleasure and profit by all who are interested in the subject. G. LAPAGE

\section{Histologie und Mikroskopische Anatomie des} Menschen

Von Dr. W. Bargmann. 5. überarbeitete Auflage. Pp. xvi + 856. (Stuttgart: Goorg Thieme Verlag, 1964.) 72 D.M. 7 Hears, already in its fifth German edition, and that the second Spanish edition is in preparation, speaks for the author's thoroughness in revision and his desire to keep up with recent developments. The text is based on a correlation of histology with physiology, biochemistry and submicroscopic morphology on one hand, and where applicable to pathology on the other. The text is divided into two parts. The first deals with general eytology and a descriptive exposé of the tissues: epithelial, supporting, muscular and nervous.

The second part considers the organs and organic systems: locomotor, circulatory and defensive, internal, secretory, digestive, respiratory, urinary, sexual, cutanoous, sensory, and central nervous systems. The text is lucid and integration of the different disciplines is excellent although some might find a more extensive discussion. of tissue culture morphology of advantage. Literature references are ample and not confined to German publications. The illustrations are of excellent quality, but, as they are not indicated in the index, are sometimes hard to find if a particular one is sought. Another criticism, which applies to most publications, is that magnifications mentioned do not indicate whether they apply to the finished product or are applicable to some previous stage in their production. Both referenco and subject indexes are adequate with the aforementioned reservation.

In conclusion this book is of general interest and, because of the illustrations, might even prove us oful to workors who have only a limited knowledge of German. G. SANDER 